\title{
Higher expression of calcineurin predicts poor prognosis in unique subtype of ovarian cancer
}

\author{
Bing Xin ${ }^{1 *}$, Kai-Qiang Ji², Yi-Si Liư and Xiao-Dong Zhao ${ }^{3}$
}

\begin{abstract}
Background: The role of calcineurin/NFAT signaling in ovarian cancer has been unknown. NFAT was significantly overexpressed in ovarian cancer tissues and that overexpression of NFAT was significantly associated with metastasis and poor prognosis on clinical tissue level. To investigate whether NFAT upstream protein, calcineurin $(\mathrm{CN})$, affects the prognosis in various histological subtype of ovarian cancer (OC).

Methods: The association between CN and clinical features was analyzed in 50 OC patients treated from 2007 to 2012. CN expression was examined using immunohistochemistry. We observed the association of CN expression with the prognosis in these patients.

Results: CN expression was significantly increased in later-stage tumor tissue of serous carcinoma compared with those with early-stage. The expression of CN positively correlated with the serum cancer antigen 125 (CA125) level in ovarian clear-cell carcinoma and the serum alpha-fetoprotein (AFP) level in papillary serous cystadenocarcinoma. Particularly, higher CN expression in tumor tissues significantly correlated with reduced overall survival among patients with serous carcinoma. In addition, the serum cancer antigen 72-4 (CA72-4) level, serum carcinoembryonic antigen (CEA) levels, pathological stage, lymph node metastasis, and chemotherapeutic resistance were identified as significant prognostic factors in ovarian clear-cell carcinoma, serous carcinoma, or papillary serous cystadenocarcinoma.

Conclusions: $\mathrm{CN}$ is upregulated in ovarian cancer tissues with later-stage and that the expression of CN, CA72-4, and CEA was remarkably associated with poor prognosis in unique subtype of ovarian cancer. CN levels may be investigated for use as a prognostic biomarker for risk assessment in unique subtype of OC patients.
\end{abstract}

Keywords: Calcineurin, Prognosis, Histological subtype, Ovarian cancer, Carcinoembryonic antigen, Cancer antigen $72-4$

\section{Background}

Ovarian cancer $(\mathrm{OC})$ is the leading cause of death from gynecological malignancies, accounting for $4 \%$ of all cancers in women in the worldwide [1]. Ovarian cancers can be classified into three large groups: epithelial, germ cell, and specialized stromal cell tumors. The vast majority of ovarian cancers are epithelial ovarian cancers (EOCs). EOC can be further subdivided into various histological subtypes that fall into two main groups:

\footnotetext{
* Correspondence: Xinb@sj-hospital.org

'Department of Gynaecology, Shengjing Hospital of China Medical

University, No.36 Sanhao Street, Heping District, Shenyang 110004, China

Full list of author information is available at the end of the article
}

Type I and Type II tumors. Type I tumors include lowgrade serous, mucinous, endometrioid, clear cell carcinomas and tend to grow more slowly, often from an identifiable precursor. In contrast, Type II tumors are characterized by high-grade and rapidly progressive disease. High-grade serous ovarian carcinoma and papillary serous cystadenocarcinomas are the most common Type II tumor. Unfortunately, it is also one of the most aggressive. Patients with stage III or IV disease have a dismal $25 \%$ 5-year survival rate [2]. In spite of improvements of treatment, survival rates for patients with advanced disease remain gloomy [3]. However, the molecular mechanism of ovarian cancer initiation and

(C) The Author(s). 2019 Open Access This article is distributed under the terms of the Creative Commons Attribution 4.0 International License (http://creativecommons.org/licenses/by/4.0/), which permits unrestricted use, distribution, and 
progression has been still poorly understood. Therefore, it is essential to understand its molecular mechanism before establishing novel therapeutic and diagnostic strategies against the deadly disease.

Calcineurin $(\mathrm{CN})$ is composed of two subunits, a catalytic subunit called calcineurin A (CNA) encoded by three separate genes (PPP3CA, PPP3CB and PPP3CC), and a regulatory subunit, calcineurin $\mathrm{B}(\mathrm{CNB})$ encoded by two genes, PPP3R1 and PPP3R2, with the latter restricted to testis and brain. $\mathrm{CN}$ is a calcium dependent serine/threonine phosphatase that plays a central role in immunity, as demonstrated by the use of calcineurin inhibitors cyclosporine A and tacrolimus (FK506) as immunosuppressants [4]. In the presence of elevated calcium, calmodulin binds to calcineurin, displacing the autoinhibitory domain from the active site, leading to activation of calcineurin and subsequent dephosphorylation of target proteins. Calcineurin substrates include transcription factors, proteins involved in cell cycle and apoptosis, cytoskeletal proteins, scaffold proteins, membrane channels and receptors [5]. The best characterized calcineurin substrates are the nuclear factor of activated $\mathrm{T}$ cells (NFAT) transcription factors. Following dephosphorylation by calcineurin, NFAT is translocated to the nucleus where it regulates gene expression. The calcineurin/NFAT pathway is activated in diagnostic breast cancer cases and is essential to survival and metastasis of mammary cancer cells [6]. However, the role of calcineurin/NFAT signaling in ovarian cancer has been unknown.

Recently study revealed that both knockdown and reexpression of NFAT on ovarian cancer cells were employed to observe the effect overgrowth [7]. It was found that NFAT was significantly overexpressed in ovarian cancer tissues in comparison with paired normal control tissues and that overexpression of NFAT was significantly associated with metastasis and poor prognosis on clinical tissue level [7]. Thus, this study aims to investigate whether NFAT upstream protein, calcineurin, affects the prognosis in various histological subtype of ovarian cancer, we have detected the status of calcineurin expression in ovarian cancer tissues and analyzed its clinicopathological significance of calcineurin expression.

\section{Materials and methods \\ Patients}

The retrospective study cohort consisted of 50 ovarian cancer patients (19 clear-cell carcinoma, 15 serous carcinoma and 16 papillary serous cystadenocarcinoma) with ovarian cancer who underwent surgical resection at Shengjing Hospital in China between 2007 and 2012. The clinical and pathological characteristics were obtained from patient charts. Tumors were staged according to the Seventh Edition of the Cancer Staging Manual by the American Joint Committee on Cancer, and the histological grade was scored according to the World Health Organization classification. This study was approved by the Ethics Committee of Shengjing Hospital (No.2017PS233K), and written informed consent was obtained from each patient.

\section{Immunohistochemical staining}

Tissues were fixed in formalin and embedded in paraffin, and $2-\mu \mathrm{m}$-thick consecutive sections were sliced and mounted on glass slides. The slides were first incubated at $65^{\circ} \mathrm{C}$ for $30 \mathrm{~min}$ and then subjected to deparaffinization in xylene followed by rehydration in a graded ethanol series. Then, the sections were boiled in Trilogy reagent (Cell Marque, Rocklin, CA, USA) for $10 \mathrm{~min}$ for antigen retrieval. After washing with $1 \times \mathrm{PBS}$, the slides were immersed in $3 \%$ hydrogen peroxide for $10 \mathrm{~min}$ to suppress endogenous peroxidase activity. After three rinses with $1 \times \mathrm{PBS}$, the sections were exposed to a mouse anti-calcineurin antibody (Genetex, Irvine, CA, USA) for $1 \mathrm{~h}$ at room temperature. After three rinses with $1 \times \mathrm{PBS}$, the slides were incubated in a biotinylated secondary antibody (Dako, Glostrup, Denmark) for 25 min. The slides were then rinsed three times with $1 \times$

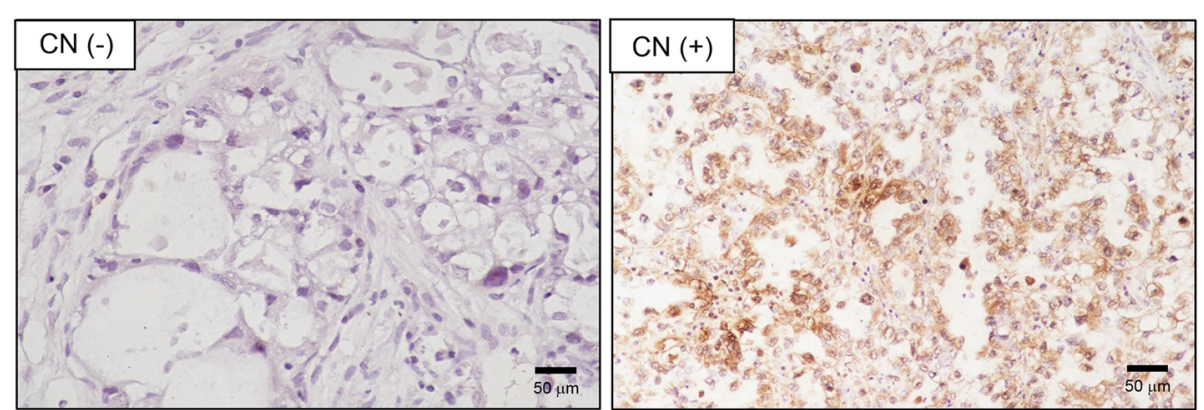

Fig. 1 Immunohistochemical staining for $\mathrm{CN}$ in ovarian cancer. The tumor tissues of ovarian cancer patients were analyzed for $\mathrm{CN}$ expression by immunohistochemical staining as described in Methods. $\mathrm{CN}(-)$ indicated the $\mathrm{CN}$-negative expression; $\mathrm{CN}(+)$ indicated the $\mathrm{CN}$-positive expression. Scale bar: $50 \mu \mathrm{m}$ 


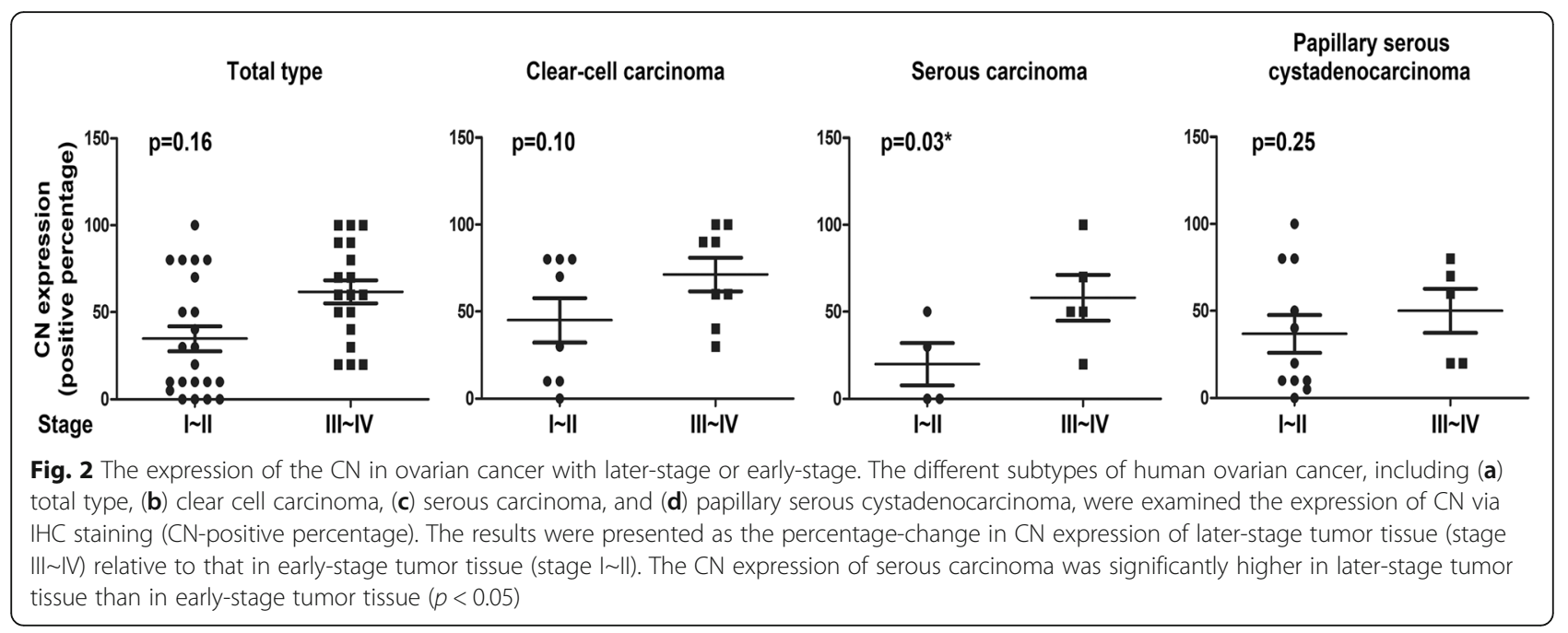

PBS, followed by the addition of horseradish peroxidase (HRP)-conjugated streptavidin for $25 \mathrm{~min}$ at room temperature. Peroxidase activity was detected by incubating the slides in the chromogenic substrate 3, $3^{`}$-diaminobenzidine (DAB) (Dako) at room temperature. The slides were then counterstained with hematoxylin.

\section{Statistical analysis}

The original IHC data were recorded as continuous variables and were analyzed using Mann-Whitney $U$-test. Kaplan-Meier curve with log-rank test presenting the disease-free survival and overall survival of ovarian cancer exhibiting high or low $\mathrm{CN}$ expression. All statistical analyses were performed using SPSS 16.0 and Excel 2007 software. All statistical tests were two-sided, and the thresholds for significance were set at $P<0.05\left(^{*}\right)$.

\section{Results}

$\mathrm{CN}$ is downregulated in later-stage tumors in unique subtype of ovarian cancer

To analyze the biological significance of $\mathrm{CN}$ expression in various histological subtype of ovarian cancer, the levels of $\mathrm{CN}$ were analyzed in 19 clear-cell carcinoma, 15 serous carcinoma and 16 papillary serous cystadenocarcinoma via immunohistochemical staining. The $\mathrm{CN}$ expression was assessed by the percentage of $\mathrm{CN}$-positive cells in tumor tissues (Fig. 1). The $\mathrm{CN}$ expression in different stage of tumor tissue in ovarian cancer is shown in Fig. 2. Compared with early-stage (I II) tumor tissue, the CN expression was significantly increased in later-stage (III IV) tumor tissue of serous carcinoma $(p<$ 0.05). Further, we evaluated the association of $\mathrm{CN}$ expression with tumor size in various histological subtype of ovarian cancer. Consistently, upregulation of $\mathrm{CN}$

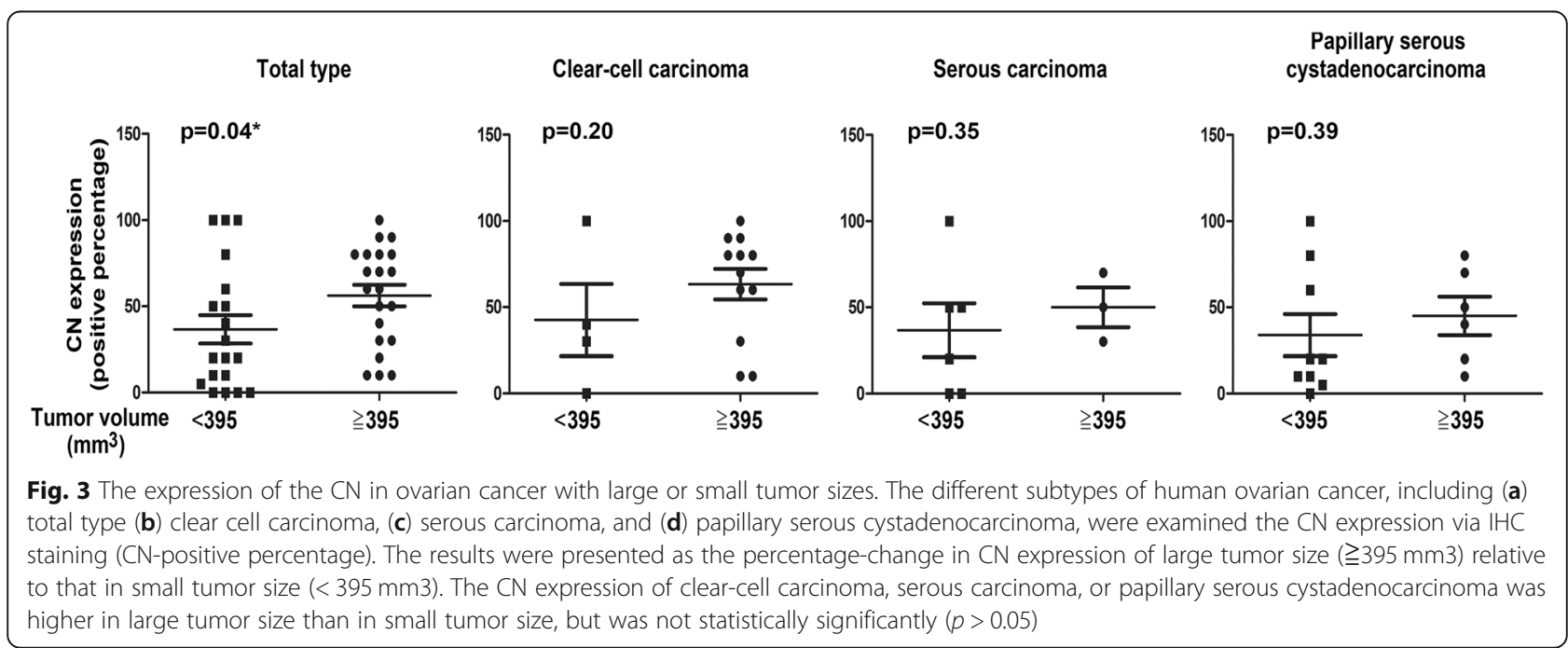


Table 1 Nonparametric analysis of CN expression in relation to various clinical parameters

\begin{tabular}{|c|c|c|c|c|c|c|c|c|c|c|c|c|}
\hline \multirow{3}{*}{$\begin{array}{l}\text { Clinical } \\
\text { parameters }\end{array}$} & \multicolumn{12}{|c|}{ CN expression } \\
\hline & \multicolumn{3}{|c|}{ Total type } & \multicolumn{3}{|c|}{ Clear-cell carcinoma } & \multicolumn{3}{|c|}{ Serous carcinoma } & \multicolumn{3}{|c|}{ Papillary serous cystadenocarcinoma } \\
\hline & $\mathrm{N}$ & Mean \pm SD & $p$-value & $\mathrm{N}$ & Mean \pm SD & $p$-value & $\bar{N}$ & Mean $\pm S D$ & $p$-value & $\mathrm{N}$ & Mean \pm SD & $p$-value \\
\hline \multicolumn{13}{|l|}{ Age (years) } \\
\hline$<50$ & 20 & $38.25 \pm 35.81$ & 0.14 & 9 & $51.11 \pm 38.87$ & 0.63 & 3 & $26.67 \pm 25.17$ & 0.38 & 8 & $28.13 \pm 34.43$ & 0.15 \\
\hline$\geqq 50$ & 21 & $53.33 \pm 30.39$ & & 8 & $60.00 \pm 31.17$ & & 6 & $48.33 \pm 35.50$ & & 7 & $50.00 \pm 28.28$ & \\
\hline \multicolumn{13}{|c|}{ Pathological stage } \\
\hline $\mid \sim \|$ & 22 & $31.00 \pm 22.73$ & 0.16 & 8 & $45.00 \pm 21.86$ & 0.10 & 4 & $18.00 \pm 22.50$ & $0.03^{*}$ & 10 & $25.00 \pm 31.23$ & 0.25 \\
\hline$\||| \sim \mid V$ & 18 & $60.28 \pm 33.72$ & & 8 & $71.25 \pm 22.48$ & & 5 & $58.00 \pm 21.50$ & & 5 & $45.00 \pm 32.75$ & \\
\hline \multicolumn{13}{|c|}{ Tumor size $\left(\mathrm{mm}^{3}\right)$} \\
\hline$<395$ & 20 & $35.25 \pm 35.67$ & $0.04^{*}$ & 5 & $36.00 \pm 39.12$ & 0.20 & 6 & $36.67 \pm 28.30$ & 0.35 & 9 & $33.89 \pm 36.55$ & 0.39 \\
\hline$\geqq 395$ & 21 & $56.19 \pm 28.72$ & & 12 & $63.33 \pm 30.85$ & & 3 & $50.00 \pm 20.00$ & & 6 & $45.00 \pm 27.39$ & \\
\hline \multicolumn{13}{|c|}{ LN metastasis } \\
\hline No & 24 & $31.25 \pm 31.53$ & 0.26 & 10 & $46.00 \pm 32.04$ & 0.12 & 4 & $20.00 \pm 24.50$ & 0.11 & 10 & $25.00 \pm 31.23$ & 0.25 \\
\hline Yes & 17 & $52.65 \pm 36.23$ & & 7 & $68.57 \pm 36.25$ & & 5 & $58.00 \pm 29.50$ & & 5 & $45.00 \pm 32.75$ & \\
\hline \multicolumn{13}{|c|}{ Distant metastasis } \\
\hline No & 40 & $40.13 \pm 34.02$ & 0.89 & 16 & $40.25 \pm 35.57$ & 0.68 & 9 & $41.11 \pm 32.58$ & - & 15 & $38.33 \pm 32.61$ & - \\
\hline Yes & 1 & $40 \pm 0$ & & 1 & $60 \pm 0$ & & 0 & - & & 0 & - & \\
\hline \multicolumn{13}{|l|}{ Ascites } \\
\hline No & 21 & $45.24 \pm 33.11$ & 0.88 & 10 & $52.00 \pm 34.90$ & 0.66 & 6 & $36.67 \pm 38.30$ & 0.55 & 5 & $42.00 \pm 25.88$ & 0.68 \\
\hline Yes & 20 & $46.75 \pm 34.95$ & & 7 & $60.00 \pm 36.52$ & & 3 & $50.00 \pm 20.00$ & & 10 & $36.50 \pm 36.67$ & \\
\hline \multicolumn{13}{|c|}{ Chemotherapeutic response } \\
\hline No & 2 & $50.00 \pm 56.57$ & 0.91 & 1 & $90.00 \pm 0$ & 0.32 & 0 & - & - & 1 & $10 \pm 0$ & 0.62 \\
\hline Yes & 32 & $47.34 \pm 33.41$ & & 13 & $53.85 \pm 35.72$ & & 7 & $50.00 \pm 31.09$ & & 12 & $38.75 \pm 33.04$ & \\
\hline \multicolumn{13}{|c|}{ Chemotherapeutic resistance } \\
\hline No & 18 & $35.83 \pm 30.01$ & 0.49 & 5 & $46.00 \pm 28.81$ & 0.81 & 2 & $15.00 \pm 21.21$ & - & 11 & $35.00 \pm 31.86$ & 0.49 \\
\hline Yes & 8 & $45.00 \pm 33.81$ & & 4 & $42.50 \pm 35.00$ & & 0 & - & & 4 & $47.50 \pm 37.75$ & \\
\hline \multicolumn{13}{|c|}{ CA125 (U/ml) } \\
\hline$<324$ & 22 & $48.86 \pm 34.22$ & 0.66 & 11 & $51.82 \pm 37.10$ & $0.04^{*}$ & 3 & $50.00 \pm 20.00$ & 0.55 & 8 & $44.38 \pm 37.36$ & 0.61 \\
\hline$\geqq 324$ & 18 & $44.44 \pm 33.47$ & & 5 & $72.00 \pm 21.68$ & & 6 & $36.67 \pm 38.30$ & & 7 & $31.43 \pm 27.34$ & \\
\hline \multicolumn{13}{|c|}{ CA19-9 (U/ml) } \\
\hline$<21.55$ & 21 & $50.00 \pm 37.68$ & 0.69 & 8 & $65.00 \pm 34.23$ & 0.90 & 6 & $41.67 \pm 39.71$ & 1.00 & 7 & $40.00 \pm 39.58$ & 0.71 \\
\hline$\geqq 21.55$ & 17 & $44.71 \pm 28.75$ & & 7 & $50.00 \pm 36.52$ & & 3 & $40.00 \pm 17.32$ & & 7 & $41.43 \pm 26.73$ & \\
\hline \multicolumn{13}{|c|}{ CA72-4 (U/ml) } \\
\hline$<7.89$ & 19 & $47.89 \pm 37.94$ & 0.98 & 8 & $58.75 \pm 39.80$ & 0.83 & 3 & $23.33 \pm 40.42$ & 0.38 & 8 & $46.25 \pm 35.43$ & 0.39 \\
\hline$\geqq 7.89$ & 21 & $45.95 \pm 29.90$ & & 8 & $57.50 \pm 29.16$ & & 6 & $50.00 \pm 27.57$ & & 7 & $29.29 \pm 28.93$ & \\
\hline \multicolumn{13}{|l|}{$\operatorname{AFP}(\mathrm{ng} / \mathrm{mL})$} \\
\hline$<2.9$ & 22 & $28.86 \pm 20.08$ & 0.24 & 7 & $57.14 \pm 27.52$ & 0.63 & 3 & $40.00 \pm 36.06$ & 0.91 & 12 & $6.67 \pm 5.77$ & $0.03^{*}$ \\
\hline$\geqq 2.9$ & 18 & $44.44 \pm 28.08$ & & 9 & $58.88 \pm 39.51$ & & 6 & $41.67 \pm 34.30$ & & 3 & $46.25 \pm 31.70$ & \\
\hline \multicolumn{13}{|c|}{ CEA (ng/mL) } \\
\hline$<1.48$ & 17 & $48.82 \pm 27.36$ & 0.83 & 8 & $45.00 \pm 34.23$ & 0.14 & 4 & $47.50 \pm 320.62$ & 0.56 & 5 & $56.00 \pm 23.02$ & 0.15 \\
\hline$\geqq 1.48$ & 22 & $47.05 \pm 38.07$ & & 8 & $71.25 \pm 29.49$ & & 5 & $36.00 \pm 41.59$ & & 9 & $31.67 \pm 35.36$ & \\
\hline
\end{tabular}

Statistical analysis using Mann-Whitney $U$ test; LN, lymph node; CA125, cancer antigen 125; CA19-9, cancer antigen 19-9; CA72-4, cancer antigen 72-4; AFP, alpha-fetoprotein; CEA, carcinoembryonic antigen; ${ }^{*} \mathrm{p}<0.05$ 
expression was observed in large tumor size $\left(>395 \mathrm{~mm}^{3}\right)$ of total types (Fig. 3, $p<0.05$ ), but was not statistically significantly in large tumor size of each subtype (Fig. $3, p>0.05)$. The results suggested its potential function as a tumor progressor in ovarian serous carcinoma.

\section{The upregulation of $\mathrm{CN}$ expression is associated with a poor prognosis in unique subtype of ovarian cancer}

To determine the clinical significance of $\mathrm{CN}$ expression in various histological subtype of ovarian cancer, we performed linear regression analysis using these samples. The examined clinical characteristics of the patients included the following: age, pathological stage, tumor size, lymph node metastasis, distant metastasis, ascites formation, chemotherapeutic response, chemotherapeutic resistance, and the levels of cancer antigen 125 (CA125), cancer antigen 19-9 (CA19-9), cancer antigen 72-4 (CA72-4), alpha-fetoprotein (AFP), and carcinoembryonic antigen (CEA). These characteristics of the recruited ovarian cancer patients are summarized in Table 1. Based on univariate analysis, the $\mathrm{CN}$ expression positively correlated with pathological stage in ovarian serous carcinoma, with serum CA125 level in ovarian clear-cell carcinoma, and with serum AFP level in ovarian papillary serous cystadenocarcinoma (Table $1, p<0.05$ ). No significant associations of $\mathrm{CN}$ expression with other clinical or pathological parameters were found (Table 1).

We further determined whether the $\mathrm{CN}$ expression correlated with survival outcomes of patients with ovarian cancer after surgery. Kaplan-Meier survival analysis followed by the log-rank test showed that higher $\mathrm{CN}$ expression (expression level $>50 \%$ ) in tumor tissues not significantly correlated with reduced disease-free survival among patients with each subtype (Fig. 4 and Table 2, $p>0.05)$. Particularly, higher $\mathrm{CN}$ expression in tumor tissues significantly correlated with reduced overall survival among patients with serous carcinoma (Fig. 5 and Table 3, $p<0.05)$. The results were further verified by TCGA survival data analysis (http://www.oncolnc. org/). Similarly, a catalytic subunit of $\mathrm{CN}, P P P 3 C A$, is significantly associated with reduced overall survival in ovarian serous carcinoma (Additional file 1: Figure S1, $p<0.05$ ). In addition, pathological stage, lymph node metastasis, chemotherapeutic resistance, serum CA72-4 level, serum CEA level and age were identified as significant prognostic factors in ovarian clear-cell carcinoma, serous carcinoma, or papillary serous cystadenocarcinoma, respectively (Table 2 and Table $3, p<0.05$ ).

\section{Discussion}

Ovarian cancer $(\mathrm{OC})$ is one of the most common malignant cancers worldwide and is the tenth leading cause of cancer-related death. Although clinical symptoms are not commonly observed during the early stages of OC development, in most cases, the detection of symptoms during the advanced stage leads to a poor prognosis at the time of diagnosis. Thus, the exploration of new diagnostic and therapeutic molecular targets for ovarian cancer is particularly crucial. In apparent contradiction, activation of calcineurin and its downstream targets also increases tumorigenic potential. As observed by Peuker et al. [8], calcineurin and downstream signalling pathways are activated in colorectal cancer tumors and cell lines, and inhibition of calcineurin decreases cancer stem cell survival and proliferation. Similarly, calcineurin is activated in breast cancer, specifically in triple negative breast cancer, and promotes migration and invasion in vitro and growth and metastasis in vivo $[6,9]$. Analogous findings by others support a pro-tumorigenic role for calcineurin signaling in lung, prostate, bladder, pancreatic, and liver cancer, as well as glioblastoma, melanoma and leukemia [10-18]. However, only one report has addressed the function of calcineurin in ovarian cancer. Jin et al. [19] found that Calcineurin B homologous protein isoform 2

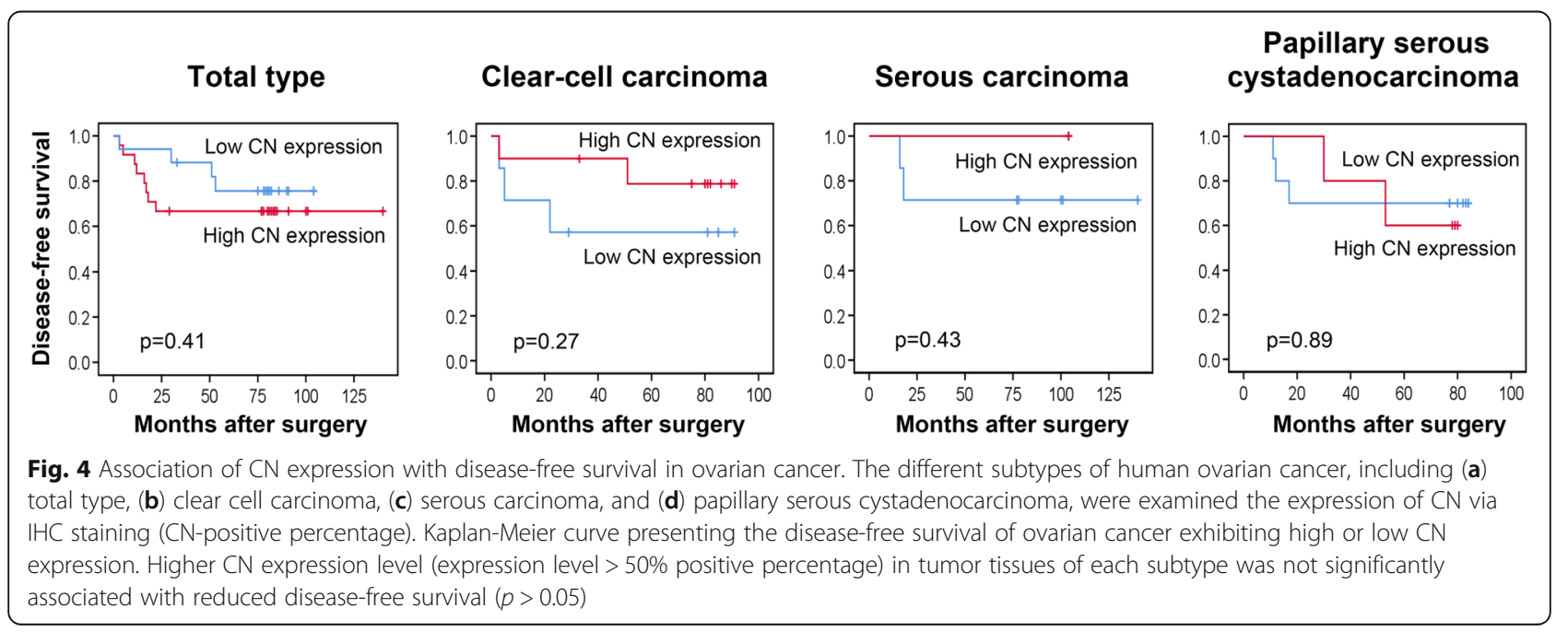




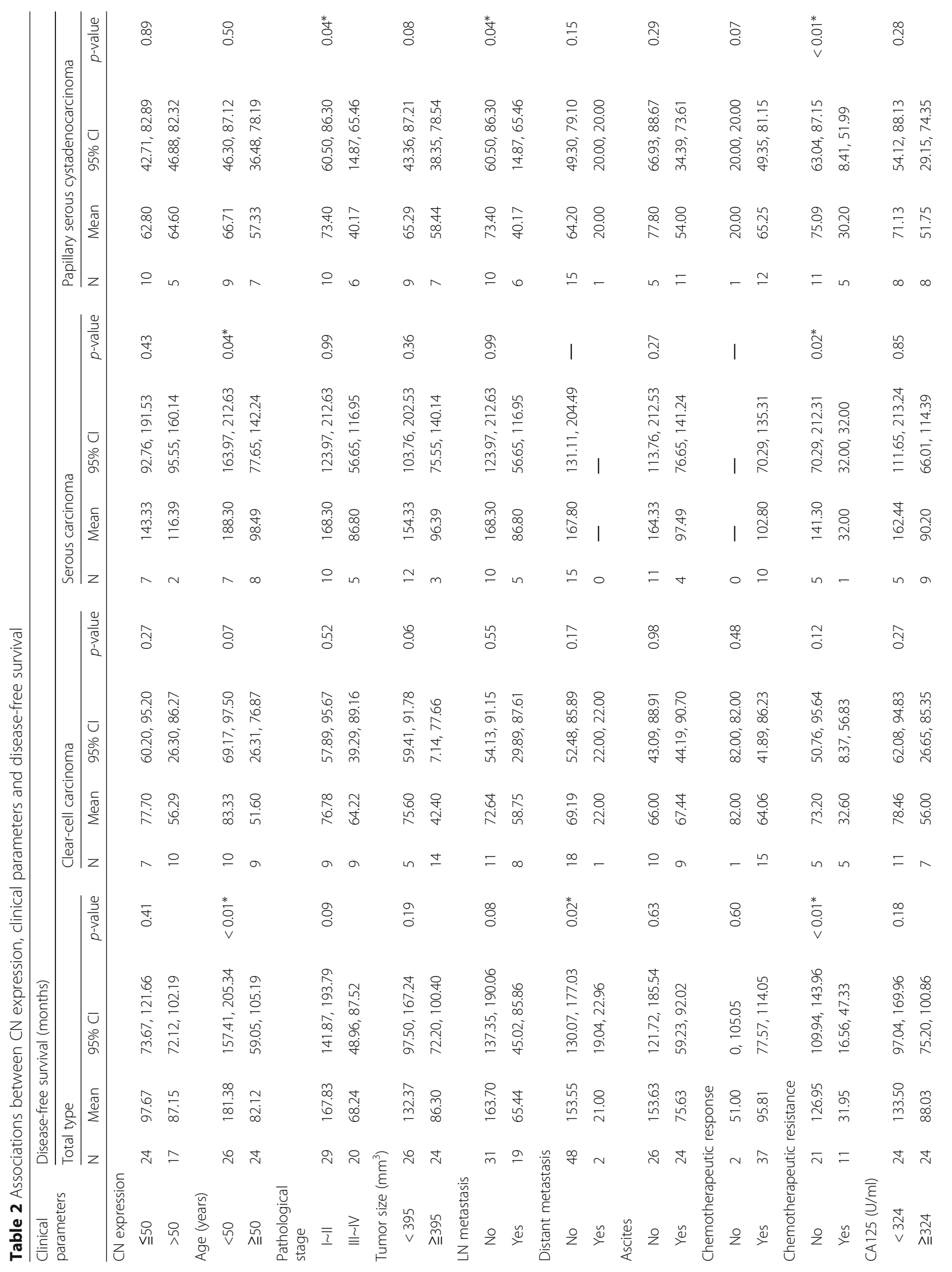




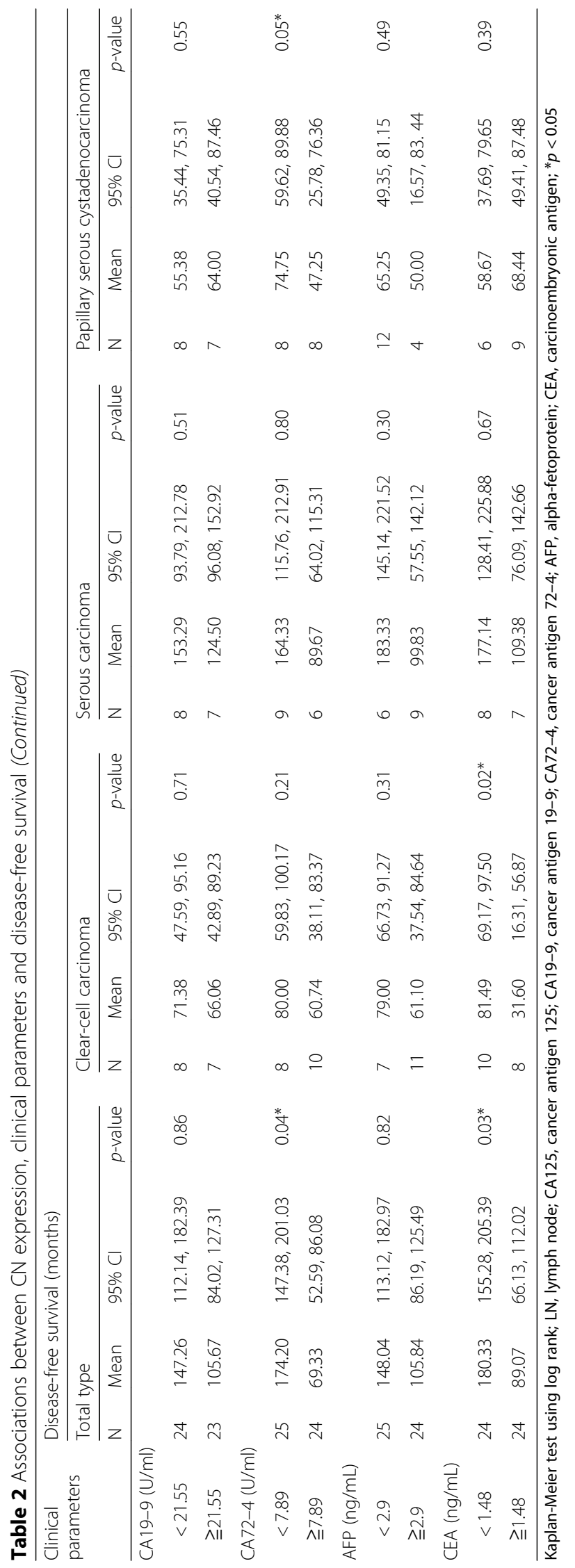




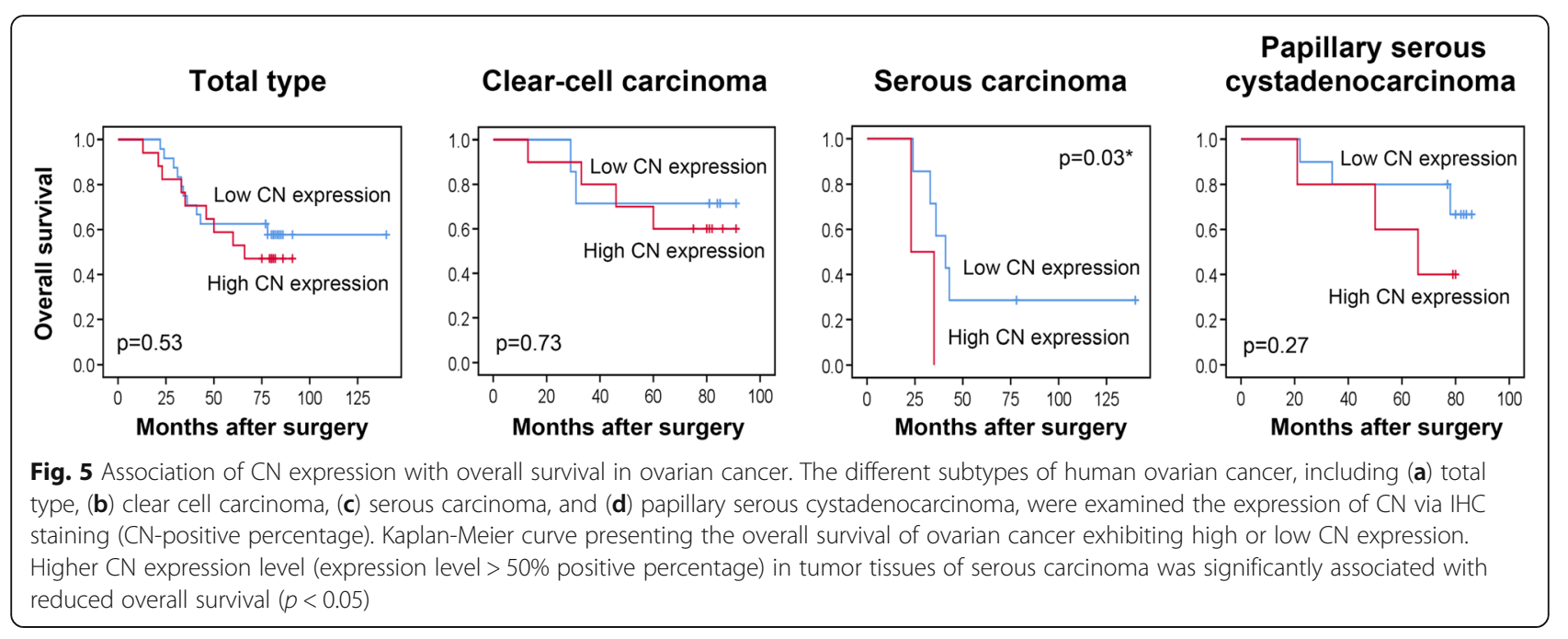

(CHP2) was identified to be expressed in ovarian cancer cell line [19]. CHP2-transfected OVCAR3 cells showed increased proliferation rates and exhibited increased activities of cell adhesion, migration and invasion [19]. Further, the present study expanded these studies and identified a potential target, calcineurin, and demonstrated its tumorprogressive effect on ovarian cancer. We found that the calcineurin expression was significantly upregulated in later-stage specimens of ovarian serous carcinoma, associated with serum CA72-4 level in ovarian clear-cell carcinoma, and that higher $\mathrm{CN}$ expression in unique subtype of ovarian cancer correlates with a poor prognostic outcome. In addition, pathological stage, lymph node metastasis, chemotherapeutic resistance, serum CA72-4 level, serum CEA level and age were identified as significant prognostic factors in ovarian clear-cell carcinoma, serous carcinoma, or papillary serous cystadenocarcinoma.

The CN/NFAT pathway is activated in diagnostic breast cancer cases and is essential to survival and metastasis of mammary cancer cells [6]. Recently, Xu et al. [20] provided clinical evidence regarding NFAT expression and its clinicopathological significance, finding that overexpression of NFAT in ovarian cancer tissues was significantly associated with metastasis and poor overall prognosis. Mechanistically, it is through activation of ERK1/2/p38/MAPK signaling pathway that NFAT upregulated the c-myc expression [20]. According to these studies, we further examined whether NFAT-related poor overall prognosis is through its upstream protein $\mathrm{CN}$. However, our data exhibited that NFAT expression was not significantly associated with $\mathrm{CN}$ expression in various histological subtype of ovarian cancer (data not shown). Taken together, we suggest that $\mathrm{CN}$-related poor overall survival may be through $\mathrm{CN}$-mediated dephosphorylation of other substrates in ovarian cancer. The substrates of $\mathrm{CN}$, including c-Jun [21], DAXX [22], BAD [23], Rb [24] and Drp1 [25], were associated with the prognosis in ovarian cancer. Further investigations should determine the intrinsic relationship of $\mathrm{CN}$ and these downstream proteins on the prognosis of ovarian cancer.

The present study showed that higher $\mathrm{CN}$ expression in ovarian serous carcinoma correlates with a poor prognostic outcome. Moreover, the results of TCGA data analysis showed that higher PPP3CA expression (a catalytic subunit of the calcineurin) is associated with reduced overall survival in ovarian serous carcinoma. Recent study reported that a novel significantly mutated gene PPP3CA in lung adenocarcinoma, but not in lung squamous cell carcinoma [26]. The mutations in PPP3CA clustered in the autoinhibitory domain near the $\mathrm{C}$-terminus suggesting it may be gain-of-function alterations [26]. Based on these findings, we suggest that $\mathrm{CN}$-related poor overall survival may be due to the mutation of PPP3CA gene in unique subtype of ovarian cancer. Certainly, it merits further investigation.

Carcinoembryonic antigen (CEA) is one of the longest known tumor antigens [27], and at present is still the most widely used tumor marker in the management of colorectal cancer $[28,29]$. Elevated serum levels of this assay were demonstrated in patients with ovarian adenocarcinomas, up to $87-88 \%$ in mucinous histotypes [30]. Elevation of preoperative serum CEA was also strongly correlated with advanced stage in patients with primary MOC and most likely indicated a poor prognosis [31]. Similarly, cancer antigen 72-4 (CA72-4), a glycoprotein, which increases in gastric, colon, breast, and ovarian adenocarcinomas, may be employed alone or in combination with CA125. CA72-4 is less sensitive than CA125 for EOC, but it is not influenced by pregnancy or the menstrual cycle, and it is only slightly influenced by inflammatory conditions [32, 33]. The present study expanded these findings and further showed that higher 


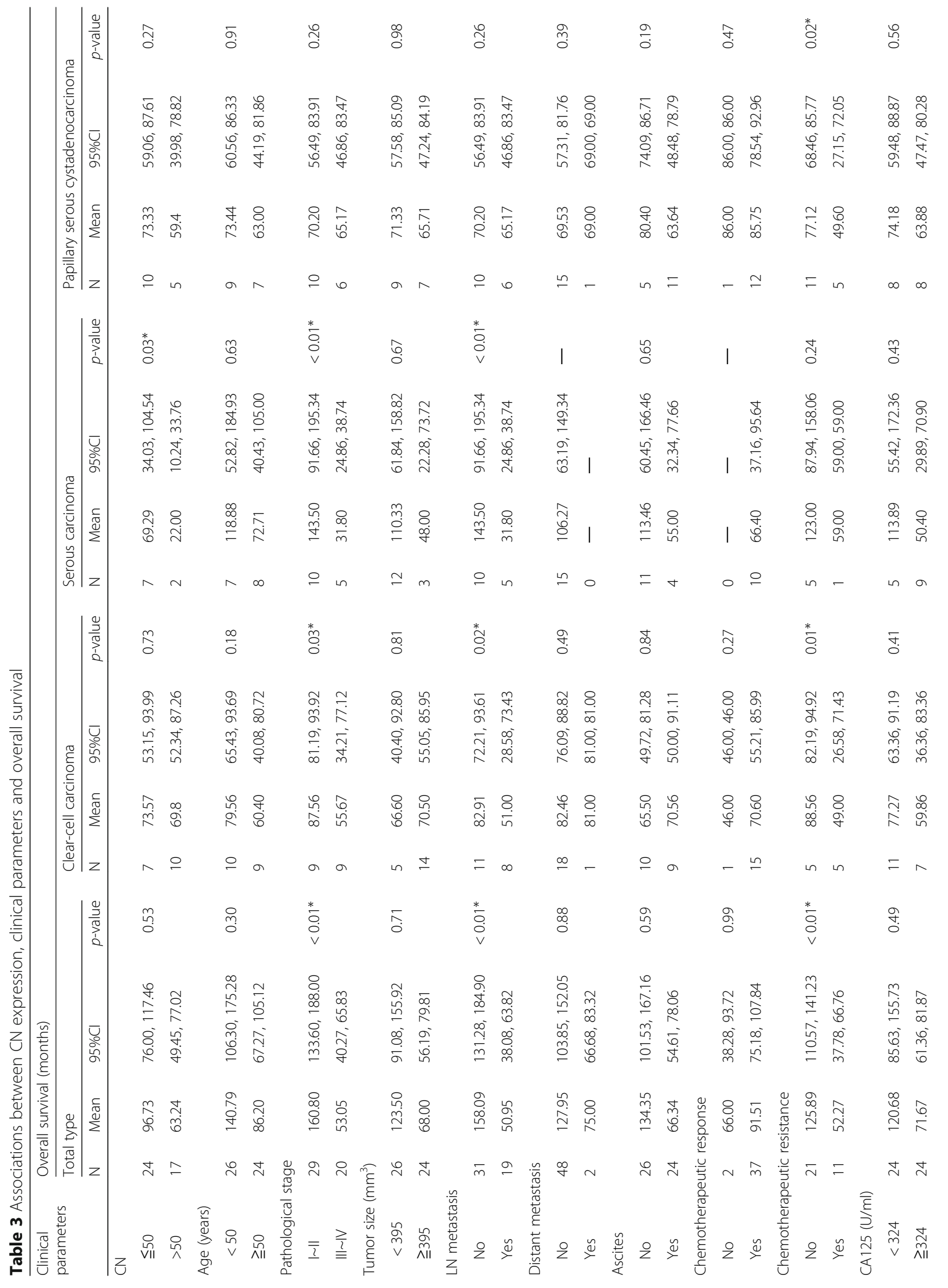




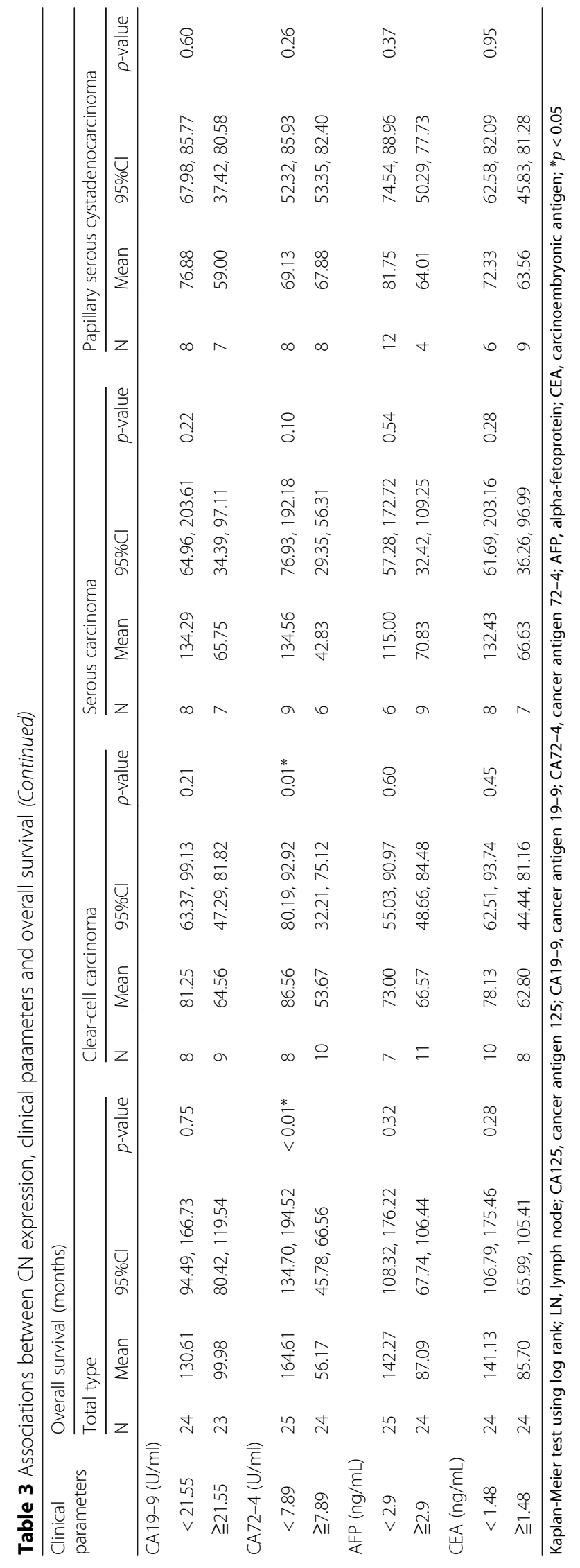


serum CEA level is associated with poor disease-free survival in patients with ovarian clear-cell carcinoma. In addition, higher serum CA72-4 level is associated with poor disease-free survival in patients with ovarian papillary serous cystadenocarcinoma and poor overall survival in patients with ovarian clear-cell carcinoma. The results indicate that CEA and CA72-4 as well as $\mathrm{CN}$ may be the potential biomarkers for the prediction of prognosis in unique subtype of ovarian cancer.

There are some limitations of the present study. First, this study is the retrospective design, thereby the possibility of residual measured or unmeasured confounding cannot be eliminated, as with any observational investigation. Second, the study was also conducted in a single hospital in an area of China noted for patients diagnosed as ovarian cancer; therefore, the results may not be generalizable to other population. Future studies must broaden the sources of ovarian cancer cases to enhance the reference of research results.

\section{Conclusion}

In the present study, we have, for the first time, found that $\mathrm{CN}$ is significantly upregulated in ovarian cancer tissues with later-stage and that the expression of $\mathrm{CN}$, CEA, and CA72-4 was remarkably associated with poor prognosis in unique subtype of ovarian cancer. $\mathrm{CN}$ levels may be investigated for use as a prognostic biomarker for risk assessment in unique subtype of ovarian cancer patients.

\section{Additional file}

Additional file 1: Figure S1. Association of CN expression with overall survival in ovarian cancer by TCGA data analysis. A pan-cancer analysis using data in OncoLnc, which linked TCGA survival data to mRNA. Kaplan-Meier curve presenting the overall survival of ovarian cancer exhibiting high or low PPP3CA (a catalytic subunit of CN) expression. Higher PPP3CA expression (expression level > 50\%) in the tumor tissues of serous carcinoma was significantly associated with reduced overall survival $(p<0.05)$. (TIF $3186 \mathrm{~kb})$

\section{Abbreviations}

AFP: alpha-fetoprotein; CA125: cancer antigen 125; CA19-9: cancer antigen 19-9; CA72-4: cancer antigen 72-4; CEA: carcinoembryonic antigen;

$\mathrm{CN}$ : calcineurin; IHC: immunohistochemistry; OC: ovarian cancer

\section{Acknowledgements}

The results published here are in part based upon data generated by the TCGA Research Network: https://www.cancer.gov/tcga.

\section{Authors' contributions}

BX designed the study, analyzed the data and drafted the manuscript. KQJ and YSL: performed IHC assay and contributed samples and patient information. XDZ: reviewed the data and drafted the manuscript. All authors read and approved the final manuscript.

\section{Funding}

Not applicable.
Availability of data and materials

The datasets used and/or analyzed during the current study are available from the corresponding author on reasonable request.

\section{Ethics approval and consent to participate}

This study was approved by the Research and Ethical Committee of Shengjing Hospital of China Medical University, China. The written informed consents were obtained from all of the participating patients prior to clinical data.

\section{Consent for publication}

The submission of this manuscript has been approved by all authors.

\section{Competing interests}

The authors confirm that there are no conflicts of interest.

\section{Author details}

'Department of Gynaecology, Shengjing Hospital of China Medical University, No.36 Sanhao Street, Heping District, Shenyang 110004, China ${ }^{2}$ Department of ICU, Shengjing Hospital of China Medical University, Shenyang 110004, China. ${ }^{3}$ Department of Pathology, Shengjing Hospital of China Medical University, Shenyang 110004, China.

Received: 25 June 2019 Accepted: 1 August 2019

Published online: 09 August 2019

References

1. Gansler T, Ganz PA, Grant M, Greene FL, Johnstone P, Mahoney M, Newman LA, Oh WK, Thomas CR Jr, Thun MJ, Vickers AJ, Wender RC, Brawley OW. Sixty years of CA: a cancer journal for clinicians. CA Cancer J Clin. 2010;60(6):345-50.

2. Siegel RL, Miller KD, Jemal A. Cancer statistics. CA Cancer J Clin. 2016;66:7-30.

3. Chang SJ, Bristow RE, Chi DS, Cliby WA. Role of aggressive surgical cytoreduction in advanced ovarian cancer. Journal of gynecologic oncology. J Gynecol Oncol. 2015;26(4):336-42.

4. Liu J, Farmer JD Jr, Lane WS, Friedman J, Weissman I, Schreiber SL. Calcineurin is a common target of cyclophilin-cyclosporin a and FKBP-FK506 complexes. Cell. 1991;66:807-15.

5. Li H, Rao A, Hogan PG. Interaction of calcineurin with substrates and targeting proteins. Trends Cell Biol. 2011;21:91-103.

6. Quang CT, Leboucher S, Passaro D, Fuhrmann L, Nourieh M, VincentSalomon A, Ghysdael J. The calcineurin/NFAT pathway is activated in diagnostic breast cancer cases and is essential to survival and metastasis of mammary cancer cells. Cell Death Dis. 2015;6:e1658.

7. Kroeger PT Jr, Drapkin R. Pathogenesis and heterogeneity of ovarian cancer. Curr Opin Obstet Gynecol. 2017;29(1):26-34.

8. Peuker K, Muff S, Wang J, Künzel S, Bosse E, Zeissig Y, Luzzi G, Basic M, Strigli A, Ulbricht A, Kaser A, Arlt A, Chavakis T, van den Brink GR, Schafmayer C, Egberts JH, Becker T, Bianchi ME, Bleich A, Röcken C, Hampe J, Schreiber S, Baines JF, Blumberg RS, Zeissig S. Epithelial calcineurin controls microbiota-dependent intestinal tumor development. Nat Med. 2016;22:506-15.

9. Jauliac S, López-Rodriguez C, Shaw LM, Brown LF, Rao A, Toker A. The role of NFAT transcription factors in integrin-mediated carcinoma invasion. Nat Cell Biol. 2002:4:540-4.

10. Buchholz M, Schatz A, Wagner M, Michl P, Linhart T, Adler G, Gress TM, Ellenrieder V. Overexpression of c-myc in pancreatic cancer caused by ectopic activation of NFATC1 and the Ca2+/calcineurin signaling pathway. EMBO J. 2006:25:3714-24.

11. Medyouf H, Alcalde H, Berthier C, Guillemin MC, dos Santos NR, Janin A, Decaudin D, de Thé $H$, Ghysdael J. Targeting calcineurin activation as a therapeutic strategy for T-cell acute lymphoblastic leukemia. Nat Med. 2007; 13:736-41.

12. Wang S, Kang X, Cao S, Cheng H, Wang D, Geng J. Calcineurin/NFATC1 pathway contributes to cell proliferation in hepatocellular carcinoma. Dig Dis Sci. 2012:57:3184-8.

13. Brun M, Glubrecht DD, Baksh S, Godbout R. Calcineurin regulates nuclear factor I dephosphorylation and activity in malignant glioma cell lines. J Biol Chem. 2013;288:24104-15.

14. Gachet $\mathrm{S}$, Genescà $\mathrm{E}$, Passaro D, Irigoyen M, Alcalde $H$, Clémenson C, Poglio S, Pflumio F, Janin A, Lasgi C, Dodier S, Soyer M, Duménil G, Ghysdael J. Leukemia-initiating cell activity requires calcineurin in T-cell acute lymphoblastic leukemia. Leukemia. 2013;27:2289-300. 
15. Minami T, Jiang S, Schadler K, Suehiro J, Osawa T, Oike Y, Miura M, Naito M, Kodama T, Ryeom S. The calcineurin- NFAT-angiopoietin-2 signaling axis in lung endothelium is critical for the establishment of lung metastases. Cell Rep. 2013;4:709-23.

16. Tie X, Han S, Meng L, Wang Y, Wu A. NFAT1 is highly expressed in, and regulates the invasion of, glioblastoma multiforme cells. PLoS One. 2013;8:e66008.

17. Manda KR, Tripathi P, Hsi AC, Ning J, Ruzinova MB, Liapis H, Bailey M, Zhang $H$, Maher CA, Humphrey PA, Andriole GL, Ding L, You Z, Chen F. NFATC1 promotes prostate tumorigenesis and overcomes PTEN lossinduced senescence. Oncogene. 2016;35:3282-92.

18. Shoshan E, Braeuer RR, Kamiya T, Mobley AK, Huang L, Vasquez ME, Velazquez-Torres G, Chakravarti N, Ivan C, Prieto V, Villares GJ, Bar-Eli M. NFAT1 directly regulates IL8 and MMP3 to promote melanoma tumor growth and metastasis. Cancer Res. 2016;76:3145-55

19. Jin Q, Kong B, Yang X, Cui B, Wei $Y$, Yang Q. Overexpression of CHP2 enhances tumor cell growth, invasion and metastasis in ovarian cancer. Vivo. 2007;21(4):593-8

20. Xu W, Gu J, Ren Q, Shi Y, Xia Q, Wang J, Wang S, Wang Y, Wang J. NFATC1 promotes cell growth and tumorigenesis in ovarian cancer up-regulating c-Myc through ERK1/2/p38 MAPK signal pathway. Tumour Biol. 2016;37(4): 4493-500.

21. Eckhoff $K$, Flurschütz $R$, Trillsch F, Mahner S, Jänicke F, Milde-Langosch K. The prognostic significance of Jun transcription factors in ovarian cancer. J Cancer Res Clin Oncol. 2013;139(10):1673-80.

22. Pontikakis S, Papadaki C, Tzardi M, Trypaki M, Sfakianaki M, Koinis F, Lagoudaki E, Giannikaki L, Kalykaki A, Kontopodis E, Saridaki Z, Malamos N, Georgoulias V, Souglakos J. Predictive value of ATP7b, BRCA1, BRCA2, PARP1, UIMC1 (RAP80), HOXA9, DAXX, TXN (TRX1), THBS1 (TSP1) and PRR13 (TXR1) genes in patients with epithelial ovarian cancer who received platinum-taxane first-line therapy. Pharmacogenomics J. 2017 17(6):506-14.

23. Stickles XB, Marchion DC, Bicaku E, Al Sawah E, Abbasi F, Xiong Y, Bou Zgheib N, Boac BM, Orr BC, Judson PL, Berry A, Hakam A, Wenham RM, Apte SM, Berglund $A E$, Lancaster JM. BAD-mediated apoptotic pathway is associated with human cancer development. Int J Mol Med. 2015;35(4):1081-7.

24. Ferguson DC, Long DJ, Smith MC, Craig-Owens LD, Means J, Fadare O, Desouki MM. Comparative analysis of Rb1, P16 and ER as diagnostic, prognostic and potential targets for therapeutic agents in ovarian epithelial tumors: an immunohistochemical study of 130 ovariancarcinomas. J Ovarian Res. 2015:8:34

25. Tsuyoshi H, Wong VKW, Han Y, Orisaka M, Yoshida Y, Tsang BK. Saikosaponin-d, a calcium mobilizing agent, sensitizes chemoresistant ovarian cancer cells to cisplatin-induced apoptosis by facilitating mitochondrial fission and G2/M arrest. Oncotarget. 2017;8(59):99825-40.

26. Campbell JD, Alexandrov A, Kim J, Wala J, Berger AH, Pedamallu CS, Shukla SA, Guo G, Brooks AN, Murray BA, Imielinski M, Hu X, Ling S, Akbani R, Rosenberg M, Cibulskis C, Ramachandran A, Collisson EA, Kwiatkowski DJ, Lawrence MS, Weinstein JN, Verhaak RG, Wu CJ, Hammerman PS, Cherniack AD, Getz G, Network CGAR, Artyomov MN, Schreiber R, Govindan R, Meyerson M. Distinct patterns of somatic genome alterations in lung adenocarcinomas and squamous cell carcinomas. Nat Genet. 2016;48(6):607-16.

27. Gold P, Freedman SO. Demonstration of tumor-specific antigens in human colonic carcinomata by immunological tolerance and absorption techniques. J Exp Med. 1965;121(3):439-62.

28. Park YA, Lee KY, Kim NK, Baik SH, Sohn SK, Cho CW. Prognostic effect of perioperative change of serum carcinoembryonic antigen level: a useful tool for detection of systemic recurrence in rectal cancer. Ann Surg Oncol. 2006;13(5):645-50

29. Takagawa R, Fujii S, Ohta M, Nagano Y, Kunisaki C, Yamagishi S, Osada S, Ichikawa $Y$, Shimada H. Preoperative serum carcinoembryonic antigen level as a predictive factor of recurrence after curative resection of colorectal cancer. Ann Surg Oncol. 2008;15(12):3433-9.

30. Sagi-Dain L, Lavie O, Auslander R, Sagi S. CEA in evaluation of adnexal mass: retrospective cohort analysis and review of the literature. Int J Biol Markers. 2015:30(4):e394-400.

31. Lin W, Cao D, Shen K. Prognostic significance of preoperative serum CEA in primary mucinous ovarian carcinoma: a retrospective cohort study. Cancer Manag Res. 2018;10:6913-20.
32. Lenhard MS, Nehring S, Nagel D, Mayr D, Kirschenhofer A, Hertlein L, Friese K, Stieber P, Burges A. Predictive value of CA 125 and CA 72-4 in ovarian borderline tumors. Clin Chem Lab Med. 2009;47(5):537-42.

33. Granato T, Midulla C, Longo F, Colaprisca B, Frati L, Anastasi E. Role of HE4, CA72.4, and CA125 in monitoring ovarian cancer. Tumour Biol. 2012;33(5):1335-9.

\section{Publisher's Note}

Springer Nature remains neutral with regard to jurisdictional claims in published maps and institutional affiliations.
Ready to submit your research? Choose BMC and benefit from:

- fast, convenient online submission

- thorough peer review by experienced researchers in your field

- rapid publication on acceptance

- support for research data, including large and complex data types

- gold Open Access which fosters wider collaboration and increased citations

- maximum visibility for your research: over $100 \mathrm{M}$ website views per year

At BMC, research is always in progress.

Learn more biomedcentral.com/submissions 